\title{
In Vitro Cytotoxic Activity against Breast, Cervical, and Ovarian Cancer Cells and Flavonoid Content of Plant Ingredients Used in a Selected Thai Traditional Cancer Remedy: Correlation and Hierarchical Cluster Analysis
}

\author{
Thammarat Tuy-on $\left(\mathbb{D},{ }^{1}\right.$ Arunporn Itharat $\mathbb{D}^{\mathrm{D}},{ }^{2,3}$ Ponlawat Maki $(\mathbb{D}){ }^{1}$ \\ Pakakrong Thongdeeying $\mathbb{D}^{2,3}$ Weerachai Pipatrattanaseree $\mathbb{D}^{2},{ }^{4}$ and Buncha Ooraikul ${ }^{5}$ \\ ${ }^{1}$ Graduate School, Faculty of Medicine, Thammasat University, Bangkok, Pathumthani 12120, Thailand \\ ${ }^{2}$ Department of Applied Thai Traditional Medicine, Faculty of Medicine, Thammasat University, Bangkok, Klongluang, \\ Pathumthani 12120, Thailand \\ ${ }^{3}$ Center of Excellence in Applied Thai Traditional Medicine, Faculty of Medicine, Thammasat University, Klongluang, Bangkok, \\ Pathumthani 12120, Thailand \\ ${ }^{4}$ Regional Medical Science Center 12 Songkhla, Department of Medical Sciences, Ministry of Public Health, Muang, \\ Songkhla 90100, Thailand \\ ${ }^{5}$ Department of Agricultural Food and Nutritional Science, Faculty of Agricultural Life and Environmental Sciences, \\ University of Alberta, Edmonton, AB, Canada
}

Correspondence should be addressed to Arunporn Itharat; iarunporn@yahoo.com

Received 22 August 2020; Revised 25 October 2020; Accepted 7 November 2020; Published 17 November 2020

Academic Editor: Mohd Fadzelly Abu Bakar

Copyright $\odot 2020$ Thammarat Tuy-on et al. This is an open access article distributed under the Creative Commons Attribution License, which permits unrestricted use, distribution, and reproduction in any medium, provided the original work is properly cited.

\begin{abstract}
This study aimed to investigate in vitro cytotoxic activity of selected plant ingredients from a traditional Thai remedy for the treatment of cancer patients against cancer cells occurring in women such as MCF-7 (breast cancer), SKOV3 (ovarian cancer), and HeLa (cervical cancer) cell lines. The plants and the remedy were macerated with 95\% ethanol and boiled in water. Cytotoxic activity of the extracts was analyzed by SRB assay. Total flavonoid contents of the extracts were determined and their correlation with cytotoxic activity was evaluated. The hierarchical cluster analysis (HCA) was used to classify the extracts by their cytotoxic characteristics. A total of $66.7 \%$ of the plants was active against the tested cancer cell lines. Among the 44 plants in the remedy used for cancer treatment, nine plants that are also used in Thai cuisine exerted significant cytotoxicity against tested cancer cell lines. Eleven plants in the remedy were active against at least one of the tested cancer cell lines. All extracts were grouped into three groups and illustrated as heat map and hierarchical dendrogram. Total flavonoid content showed weak or no correlation with cytotoxic activity. A. dahurica, F. albopurpurea, and T. indica selectively exerted potent cytotoxic activity against MCF-7 with SI value more than 6. A. galanga, P. amarus, L. striatum, H. indicum, and F. vulgare exerted moderate cytotoxicity to all tested cell with low toxicity to normal cells. The correlation and HCA performed in this study provided an alternative way to investigate biological activities of plant ingredients in polyherbal traditional remedies.
\end{abstract}

\section{Introduction}

Cancers of breast, cervical, and ovarian are common cancers occurring in the female population. Breast cancer is the most common and the most leading cause of cancer death among women worldwide. Cervical and ovary cancers are the fourth and seventh most common, respectively [1]. Although each cancer has its own established treatment guidelines, the conventional treatments are surgery, radiation, and chemotherapy. The current treatments, particularly anticancer 
drugs, may be inadequate for patients due to some severe side effects arising from toxicity on normal cells or tissues. These side effects of chemotherapy often affect patient's quality of life [2]. Therefore, novel substances or plant extracts need to be developed for the treatment and prevention of cancers.

Herbal medicines for cancer treatment are known to cancer patients. These medicinal plants have become increasingly recognized either as alternative medicines for cancer treatment or dietary supplements for cancer prevention. In Thai traditional medicine (TTM) prescribed by traditional doctors, several medicinal plants are combined as remedies [3, 4]. TTM is a cultural heritage and indigenous wisdom that has been used by Thai people for over a thousand years. It utilizes several herbs rather than a single herb to design a remedy for cancer treatment. The selected TTM remedy in this study was a cancer remedy prescribed at the Jitmeatta Mercy Foundation for Cancer Patients of Thailand (JFCT), Phetchaburi province, Thailand. This remedy is composed of 44 plants mixed by equal weight. This traditional cancer remedy was prepared by the decoction method and it was used to treat cancer patients more than 30 years ago. Previous research showed that almost all cancer patients treated at JFCT were women, so this research pointed to prove that this cancer remedy can cure cancers in women [5].

Phytochemical compounds in herbal medicines play an important role in the expression of biological and pharmacological activities. Flavonoids, a group of phenolic compounds, provide potential benefits in health promotion and prevention of several chronic diseases including cancer. Due to the variation of substitutions on the skeletal structure of flavonoids, an extremely diverse range of flavonoid derivatives in herbal medicines have been discovered [6]. Many flavonoids showed cytotoxic activity and antitumor, such as epigallocatechin gallate and quercetin [7].

Thus, the aim of this study was to investigate in vitro cytotoxic activity of the extracts of this TTM remedy and its 44 plant ingredients in this remedy against commonly occurring cancers in women, i.e., MCF-7 (breast cancer), SKOV3 (ovarian cancer), and HeLa (cervical cancer). The total flavonoid content of the extracts was also studied, and its correlation with cytotoxic activity was also evaluated. The statistical cluster analysis was used to visualize the cytotoxic pattern of plants and remedies. This study also evaluated an alternative method for screening the cytotoxic activity of plant ingredients in polyherbal remedies used in traditional medicines. The correlation of cytotoxic activity with total flavonoid content may be used in the search for cytotoxic compounds from flavonoids against cancers occurring in women in the future.

\section{Materials and Methods}

2.1. Plant Materials. All plants were collected from Phetchaburi Province, Thailand, in 2018. The herbarium specimens were prepared and deposited at the herbarium of Southern Center of Thai Medicinal Plants at the Faculty of Pharmaceutical Science, Prince of Songkla University, Songkhla, Thailand, and the relevant voucher numbers are shown in Table 1.
2.2. Preparation of Plant and TTM Extracts. Each plant was washed, thinly sliced, dried in an oven at $45^{\circ} \mathrm{C}$, and powdered. Dried plants (1000 g) were macerated with $3.0 \mathrm{~L}$ of $95 \%$ ethanol for 3 days, filtered, and evaporated to dryness. The selected traditional Thai cancer remedy was prepared according to the proportion used at the JFCT foundation by combining an equal weight of each dried plant, mixed together, and powdered. The resulting remedy was extracted by two methods, maceration (as described above), and decoction. The decoction method was carried out by boiling the remedy ( $1000 \mathrm{~g}$ ) with an equal amount of water for 15 minutes and the aqueous extract filtered and evaporated to dryness with a freeze drier. The ethanolic extract of TTM was named TTE and the aqueous extract obtained from decoction was named TTW. The \%yield was calculated (Table 1) and all extracts were kept at $-20^{\circ} \mathrm{C}$ until use.

2.3. Cell Lines and Culture. Breast cancer cell lines (MCF-7 ATCC NO HTB-22), ovarian cancer (SKOV-3 ATCC NO HTB-77), and cervical cancer (HeLa ATCC NO CCL-2) were purchased from the American Type Culture Collection (Manassas, VA, USA). Normal human keratinocyte immortal cell line (HaCat) was purchased from the CLS cell line service (No. 300493-SF).

MCF-7 and HeLa cell lines were cultured in minimum essential medium (MEM). SKOV-3 was cultured in Roswell Park Memorial Institute medium 1640 (RPMI-1640) and HaCat was cultured in Dulbecco's Modified Eagle's Medium (DMEM). All cultured media were supplemented with $10 \%$ fetal bovine serum and $1 \%$ penicillin-streptomycin. The cells were incubated in $5 \% \mathrm{CO}_{2}$ at $37^{\circ} \mathrm{C}$ and $95 \%$ humidity.

2.4. In Vitro Assay for Cytotoxic Activity. Cytotoxicity of the extracts was investigated by using sulphorhodamine B (SRB) assay according to the method previously described $[8,9]$. Briefly, cells were seeded in a 96-well microtiter plate and incubated for 24 hours. Each extract was diluted by DMSO to produce stock solution at a concentration of $10 \mathrm{mg} / \mathrm{ml}$ except TTW, which was diluted by water. The stock solution was diluted serially by culture medium to produce a working solution $(2,20,100$, and $200 \mu \mathrm{g} / \mathrm{ml})$. The seeded cells were treated with various concentrations of working solution of plant and remedy extracts and incubated for 72 hours. The final concentrations of extract in the seeded cell were 1,10 , 50 , and $100 \mu \mathrm{g} / \mathrm{ml}$ and the maximum final concentration of DMSO in the seeded cell was $1 \% \mathrm{v} / \mathrm{v}$. The medium was replaced with cell culture media and the plates were continuously incubated at $37^{\circ} \mathrm{C}$ for three days in order to observe cytotoxicity after a recovery period. The cells were fixed with $40 \%$ trichloroacetic acid and the plates left at $4^{\circ} \mathrm{C}$ for $45 \mathrm{~min}$. The media were removed and the cells were stained with $0.4 \%$ SRB in acetic acid. The \%survival was determined by colorimetric measurement at $492 \mathrm{~nm}$ and calculated by the following equation. The half inhibitory concentrations $\left(\mathrm{IC}_{50}\right)$ of the extracts were calculated by using GraphPad Prism software (CA, USA) 
TABLE 1: Plant ingredients in the selected Thai traditional remedy and their extraction yield (\% w/w of dried crude plant powder).

\begin{tabular}{|c|c|c|c|c|c|}
\hline Botanical name & Family & Common name & Part used & $\%$ yield & $\begin{array}{l}\text { Voucher } \\
\text { number }\end{array}$ \\
\hline Acanthus ebracteatus vahl. & Acanthaceae & Sea holly & Leaf & 3.14 & SKP 001010501 \\
\hline Andrographis paniculata (Burm.f.) Wall ex Nees. & Acanthaceae & Kariyat, Creat & Leaf & 10.23 & SKP 001011601 \\
\hline Rhinacanthus nasutus (L.) Kurz. & Acanthaceae & White crane flower & Leaf & 17.90 & SKP 001181401 \\
\hline Ananas comosus (L.)Merr. & Bromeliaceae & Pineapple & Fruit & 3.65 & SKP 029010301 \\
\hline Commiphora myrrha (NEES)Engler. & Burseraceae & Bullet Wood & Resin & 15.01 & SKP 031031301 \\
\hline Carica papaya $\mathrm{L}$. & Caricaceae & Papaya & Root & 9.64 & SKP 040031601 \\
\hline Artemisia vulgaris Linn. & Compositae & Mugwort & Rhizome & 3.29 & SKP 051012201 \\
\hline Mammea siamensis Kosterm. & Calophyllaceae & Negkassar & Flower & 5.62 & SKP 216131901 \\
\hline Mesua ferrea Linn. & Calophyllaceae & Iron wood & Flower & 4.71 & SKP216 \\
\hline Dioscorea opposite thumb. & Dioscoreaceae & Nagaimo & Rhizome & 3.14 & 041501 \\
\hline Equisetum arvense $\mathrm{L}$. & Equisetaceae & Horsetails & Leaf & 1.45 & SKP 224050101 \\
\hline Croton stellatopilosus Ohba. & Euphorbiaceae & Plow-noi (Thai) & Leaf & 14.29 & SKP 071031901 \\
\hline Phyllanthus amarus Schmach\&Thonn. & Euphorbiaceae & Egg Woman. & Leaf & 34.5 & SKP 0 \\
\hline Astragalus membranaceus Bge. Var. monglolicu. & Fabaceae & Milkvetch Root & Root & 9.12 & SKP 0 \\
\hline Heliotropium indicum L. & Fabac & Alacransillo & St & 2.98 & SKP 0 \\
\hline oides (L.f.) Royle. & Hydrocha & & & 2.18 & SKP \\
\hline Ocimum tenuiflorum $\mathrm{L}$. & Lamiaceae & Holy Basil & Leaf & 16.26 & SKP \\
\hline cablin (Blanco) Benth. & $\mathrm{La}$ & $\mathrm{P}$ & St & 27.16 & SKP \\
\hline J. Presl. & Lat & & & 12 & SKP \\
\hline Tamo & Legum & & Leaf & 12.5 & SKP 0 \\
\hline tum Dc. & Menispermaceae & Szechuan lovage & Rhizome & 10.3 & SKP 1 \\
\hline Maclura cochino & eae & Cocks & Fruit & 6.28 & SKP 1 \\
\hline Myristica fragrans Houtt. & Myri & tree. & Flo & 12.57 & SKP 12 \\
\hline Nelu & aceae & & & 1.89 & SKP 1 \\
\hline Jash & Ole & Jasmine & Flo & 20.1 & SKP 1 \\
\hline purea Seidenf. & daceae & Fading Flickingeria & Flc & 2.34 & 60101 \\
\hline$n$ halicacalum L. & & Balloon vine & & 8.38 & SKP 17 \\
\hline Min & & & & 6.92 & SKP 1 \\
\hline inensis. & raceae & Schiz & $\mathrm{Fr}$ & 14.16 & SKP 2 \\
\hline Rehmannia glutinosa (Gaertn.) libosch. & ulariac & Chine & Root & 15.0 & SKP 177180702 \\
\hline Lycium barbarum. & naceae & Goji berry, Wolfberry & & 9.81 & SKP 180120201 \\
\hline Solan & & Black nightshade & & 4.24 & SKP 1 \\
\hline Angelica sinensis (Oliv.) Diels. & Umbelliferae & Dong quai & Bulb & 2.5 & SKP 199011901 \\
\hline $\begin{array}{l}\text { Foeniclum vulgare mill subsp. piperatum (Ucr.) } \\
\text { Beguinot. }\end{array}$ & Umb & $\mathrm{Fe}$ & Fruit & 3.07 & SKP 1 \\
\hline Linacia triadra 1 & It & & e & & SKP \\
\hline hurica Benth. & $\mathrm{Umb}$ & African Tulip Tree & Bulb & 6.23 & SKP 206010401 \\
\hline Vitis vinifera $\mathrm{L}$. & & Grape & Fruit & 3.43 & SKP 204222201 \\
\hline Alpinia galangal (L.) Willd. & Zingiberaceae & Glalanga. & Rhizome & 1.78 & SKP 206010701 \\
\hline Amomum villosum Lour var. Xanthiodes. & Zingiberaceae & Bastard cardamom, & Fruit & 19.7 & SKP 206012201 \\
\hline Boesenbergia rotunda (L.) Mansf. & Zingiberaceae & Fingerroot & Rhizome & 9.62 & SKP 206021801 \\
\hline Curcuma aromatic Salisb. & Zingiberaceae & Wild Turmeric & Rhizome & 28.58 & SKP 206030101 \\
\hline ma comosa koxt & 211 & $\begin{array}{l}\text { Wanchakmodlook } \\
\text { (Thai) }\end{array}$ & Bulb & 12.96 & SKP 206030301 \\
\hline Kaempferia galanga L. & Zingiberaceae & Aromatic ginger & Rhizome & 1.14 & SKP 206110701 \\
\hline
\end{tabular}

$$
\text { Inhibition }(\%)=\left(\frac{\text { ODcontrol }- \text { ODsample }}{\text { ODcontrol }}\right) \times 100 \text {. }
$$

2.5. Total Flavonoid Content. Total flavonoid content was measured by the aluminum chloride colorimetric assay [10]. Briefly, an aliquot $(1 \mathrm{~mL})$ of the extracts or standard solution of quercetin $(20,40,60,80,100,120$, and $240 \mathrm{mg} / \mathrm{L})$ was added to a volumetric flask. To the flask were added $75 \mu \mathrm{L}$ of $5 \% \mathrm{NaNO}_{2}$ and $150 \mu \mathrm{L}$ of $10 \% \mathrm{AlCl}_{3}$. After $5 \mathrm{~min}, 500 \mu \mathrm{L}$ of $1 \mathrm{M} \mathrm{NaOH}$ was added, and the volume was adjusted by $\mathrm{H}_{2} \mathrm{O}$. The solution was mixed well, and the absorbance was measured against the prepared reagent blank at $510 \mathrm{~nm}$. The concentration of total flavonoid content in the test samples was calculated from the calibration plot $\left(Y=0.0162 x+0.0044, \quad r^{2}>0.999\right)$ and expressed as $\mathrm{mg}$ quercetin equivalent/g of dried plant. All the determinations were carried out in triplicate.

2.6. Statistical Analysis. All experiments were carried out by three independent experiments, and the data were reported as the mean and standard error of means. The correlation of total flavonoid content and cytotoxic activity was plotted and the correlation coefficient $(r)$ calculated by using 
Microsoft ${ }^{\circledR}$ excel. The similarity of cytotoxic activity to the three cancer cells of the tested plants was classified using the hierarchical cluster analysis (HCA) and visualized as a heat map using Heatmap Illustrator (HemI) version 1.0 software [11].

\section{Results}

3.1. Cytotoxic Activity. The cytotoxic activity of the plant and remedy extracts is shown in Tables 2 and 3. The extracts obtained from the selected cancer remedy, TTW and TTE, were not active $\left(\mathrm{IC}_{50}>100 \mu \mathrm{g} / \mathrm{ml}\right)$. However, TTE exerted moderate activity against MCF-7 with $\mathrm{IC}_{50}$ of $52.33 \pm 2.05 \mu \mathrm{g} / \mathrm{ml}$. Of the 46 extracts tested, $30(65.2 \%)$ exerted cytotoxic activity against the cancer cells with various degrees of potency. Four plant extracts exerted potent cytotoxic activity against MCF-7 with $\mathrm{IC}_{50}$ values less than $20 \mu \mathrm{g} / \mathrm{mL}$, including A. dahurica, M. siamensis, F. albopurpurea, and T. indica. The other 26 extracts exerted low to moderate cytotoxic activity. With regard to normal cells (HaCat), 15 extracts showed no cytotoxic activity with $\mathrm{IC}_{50}$ values more than $100 \mu \mathrm{g} / \mathrm{mL}$. The selective index (SI) of the extracts was calculated. SI is the ratio between $\mathrm{IC}_{50}$ values of HaCaT (normal cell) and cancer cell lines. The greater the SI value, the more selective it is. SI value more than 2 indicates that the herbal extract is toxic against cancer cells but less toxic to normal cells. SI value less than 2 indicates the general toxicity of the extract [12]. Based on this criterion, the extracts of. A. dahurica, F. albopurpurea, M. siamensis, C. halicacalum, C. papaya, K. galanga, P. cablin, and T. indica were remarkably selective to breast cancer (MCF-7) cells. Plant extracts which exerted activities against all tested cancer cells were from A. galaga, L. striatum, P. amarus, and H. indicum.

3.2. Total Flavonoid Content and Correlation with Cytotoxic Activity. The total flavonoid content of the extracts is shown in Table 3. C. aromatica showed the highest content $(259.7 \pm 3.21 \mathrm{mg}$ quercetin eq./g) followed by $A$. sinensis $(259.70 \pm 2.59 \mathrm{mg}$ quercetin eq./g) and $A$. dahurica $(227.95 \pm 5.69 \mathrm{mg}$ quercetin eq./g). The ethanolic extract of the Thai traditional remedy showed total flavonoid content of $105.67 \pm 4.33 \mathrm{mg}$ quercetin eq./g. The correlation between flavonoid content and cytotoxic activity of the extracts was investigated. Total flavonoid contents of the extracts were plotted against their cytotoxic activities, and the correlation coefficients $(r)$ were evaluated. The results showed that there was no correlation between the total flavonoid content of the extracts and their cytotoxic activity against all tested cell lines $(r<0.35)$ (Figure 1). However, in MCF-7, when some outlier data were excluded, there was a strong correlation between flavonoid content and cytotoxicity with $r$ value -0.81 (Figure 2).

3.3. Hierarchical Cluster Analysis. HCA is a multivariate statistical method to evaluate the pattern of data, which is classified into clusters according to their similar characteristics. The similarity or dissimilarity of the extracts is illustrated, as shown in the dendrogram (Figure 3). In this study, 44 plant extracts and two Thai traditional remedy extracts were classified by HemI software based on their cytotoxic activity against all tested cancer cells. The euclidean metric was selected to evaluate the similarity of the cytotoxic pattern. The heat map was generated to visualize the intensity of cytotoxic activity, and the linkages of similar extracts were shown in the horizontal dimension. As shown in Figure 3, HCA classified 46 extracts into three main groups. The extracts expressing low cytotoxicity against cancer cells were clustered into group I. Group II was composed of the extracts that selectively exhibited cytotoxicity against MCF-7. The extracts showing cytotoxicity against two or more cancer cells were clustered in group III.

\section{Discussion}

There has been an increasing interest in herbal medicine as an alternative treatment and prevention of cancer. Traditional Thai medicine is an alternative healthcare approach utilizing medicinal plants as a component in the holistic treatment of cancer patients [3]. In this study, we investigated the cytotoxic activity of selected Thai medicinal plants and remedy against cancer cells commonly occurred in women: breast (MCF-7), ovarian (SKOV3), and cervical cancer (HeLa). In the cytotoxic screening of 44 plants and two TTM extracts, the results were analyzed by HCA and visualized them into a heat map (Figure 3). Three major groups of the extracts were categorized by their cytotoxicity characteristics. Group I is composed of plant extracts which exerted less or no cytotoxic activity. Group II was the extracts that selectively exerted cytotoxicity against MCF-7. The extracts with moderate to high activity against all cancer cells were clustered into group III. With regard to the extracts obtained from the selected cancer remedy, TTW was not active against all tested cells, while TTE exerted moderate cytotoxicity against MCF-7. These results indicated that the cytotoxic compounds were extracted from the remedy in a small amount. However, the results of cancer treatment by TTM may occur by the accumulation of the cytotoxic compounds in the body when it was taken for long-term multiple doses. In TTM, many plants in remedy are used as many functions or biological activities related to cancer such as antiinflammation, increase immunology, antimicrobial, antioxidant activities. Another reason, TTM extract may help with another mechanism on cancer treatment such as increased immunology or angiogenesis, when this remedy was absorbed in the patient's body. Thus, this suggestion should be clarify further studied including in vivo and clinical trials investigation.

According to the heat map and HCA shown in Figure 3 along with $\mathrm{IC}_{50}$ and SI values presented in Tables 1 and 3, $A$. dahurica, F. albopurpurea, and T. indica exerted potent activity against MCF-7 with IC $_{50}$ less than $20 \mu \mathrm{g} / \mathrm{ml}$ and SI more than 6. M. siamensis exerted potent cytotoxicity against MCF-7 with SI more than 2. The results indicated that these extracts might have particularly beneficial effects for use in breast cancer treatment and prevention. A. galanga, P. amarus, and L. striatum exerted moderate 
TABLE 2: Cytotoxic activity ( $\left.\mathrm{IC}_{50} ; \mu \mathrm{g} / \mathrm{ml}\right)$ of plant extracts against breast cancer (MCF-7), ovarian cancer (SKOV3), cervical cancer (HeLa), and human keratinocyte (HaCat) cell lines (mean \pm SEM; $n=3$ ).

\begin{tabular}{|c|c|c|c|c|}
\hline \multirow{2}{*}{ Plant } & \multicolumn{4}{|c|}{ Cytotoxicity $\left(\mathrm{IC}_{50}(\mu \mathrm{g} / \mathrm{ml}) \pm \mathrm{SEM}\right)$} \\
\hline & MCF -7 & SKOV3 & Hela & HaCat \\
\hline A. ebracteatus & $>100$ & $21.52 \pm 1.28$ & $25.31 \pm 2.25$ & $80.95 \pm 0.94$ \\
\hline A. galanga & $34.79 \pm 4.24$ & $33.75 \pm 1.21$ & $34.88 \pm 1.13$ & $93.18 \pm 2.20$ \\
\hline A. villosum & $30.66 \pm 1.29$ & $80.79 \pm 3.82$ & $59.42 \pm 2.02$ & $52.25 \pm 0.58$ \\
\hline A. comosus & $>100$ & $>100$ & $>100$ & $>100$ \\
\hline A. paniculata & $87.02 \pm 3.21$ & $>100$ & $>100$ & $38.29 \pm 3.20$ \\
\hline A. sinensis & $34.15 \pm 1.33$ & $89.78 \pm 1.25$ & $72.25 \pm 2.05$ & $71.47 \pm 2.55$ \\
\hline A. dahurica & $9.87 \pm 2.13$ & $>100$ & $>100$ & $>100$ \\
\hline A. valgaris & $49.16 \pm 3.65$ & $35.44 \pm 1.07$ & $46.54 \pm 2.92$ & $27.30 \pm 3.71$ \\
\hline A. membranaceus & $>100$ & $>100$ & $>100$ & $>100$ \\
\hline B. rotunda & $29.96 \pm 1.09$ & $35.05 \pm 0.75$ & $60.22 \pm 2.15$ & $34.25 \pm 0.62$ \\
\hline C. halicacalum & $45.65 \pm 2.32$ & $>100$ & $>100$ & $>100$ \\
\hline C. papaya & $42.2 \pm 2.11$ & $>100$ & $>100$ & $>100$ \\
\hline C. verum & $20.88 \pm 1.82$ & $46.25 \pm 1.25$ & $24.12 \pm 0.88$ & $46.16 \pm 1.43$ \\
\hline C. myrrha & $>100$ & $>100$ & $68.77 \pm 4.10$ & $>100$ \\
\hline C. sativus & $>100$ & $>100$ & $>100$ & $>100$ \\
\hline C. stellatopilosus & $87.65 \pm 3.21$ & $>100$ & $>100$ & $34.21 \pm 0.10$ \\
\hline C. aromatica & $90.43 \pm 3.12$ & $>100$ & $>100$ & $8.78 \pm 0.21$ \\
\hline C. comosa & $68.56 \pm 2.32$ & $61.21 \pm 1.26$ & $73.21 \pm 2.01$ & $39.34 \pm 0.96$ \\
\hline D. opposite & $>100$ & $>100$ & $>100$ & $>100$ \\
\hline E. acoroides & $>100$ & $>100$ & $>100$ & $>100$ \\
\hline F. albopurpurea & $14.63 \pm 4.54$ & $>100$ & $>100$ & $>100$ \\
\hline F. vulgare & $20.34 \pm 2.64$ & $45.27 \pm 2.12$ & $68.25 \pm 1.85$ & $>100$ \\
\hline H. indicum & $29.55 \pm 3.21$ & $35.13 \pm 3.01$ & $47.85 \pm 2.02$ & $>100$ \\
\hline E. arvense & $>100$ & $>100$ & $>100$ & $>100$ \\
\hline J. sambac & $>100$ & $>100$ & $>100$ & $>100$ \\
\hline K. galanga & $49.33 \pm 1.45$ & $>100$ & $>100$ & $>100$ \\
\hline L. triadra & $>100$ & $46.25 \pm 3.01$ & $>100$ & $81.53 \pm 4.17$ \\
\hline L. striatum & $30.22 \pm 2.32$ & $28.32 \pm 1.52$ & $36.24 \pm 2.20$ & $>100$ \\
\hline L. barbarum & $>100$ & $>100$ & $>100$ & $>100$ \\
\hline M. cochinchinensis & $53.47 \pm 1.07$ & $>100$ & $>100$ & $37.68 \pm 0.85$ \\
\hline M. siamensis & $11.23 \pm 2.82$ & $>100$ & $>100$ & $33.39 \pm 0.40$ \\
\hline M. ferrea & $86.42 \pm 3.21$ & $>100$ & $>100$ & $6.84 \pm 0.39$ \\
\hline M. elengi & $>100$ & $>100$ & $>100$ & $>100$ \\
\hline M. fragrans & $64.57 \pm 2.22$ & $>100$ & $>100$ & $32.58 \pm 0.61$ \\
\hline N. nucifera & $>100$ & $>100$ & $>100$ & $>100$ \\
\hline O. tenuiflorum & $50.56 \pm 1.97$ & $>100$ & $>100$ & $95.08 \pm 0.59$ \\
\hline P. amarus & $23.23 \pm 1.13$ & $28.84 \pm 2.15$ & $35.21 \pm 1.08$ & $75.28 \pm 1.40$ \\
\hline P. cablin & $24.65 \pm 2.13$ & $>100$ & $>100$ & $>100$ \\
\hline R. glutinosa & $>100$ & $>100$ & $>100$ & $>100$ \\
\hline R. nasutus & $65.81 \pm 3.28$ & $48.28 \pm 3.13$ & $>100$ & $>100$ \\
\hline S. chinensis. & $>100$ & $>100$ & $>100$ & $>100$ \\
\hline S. indicum & $>100$ & $>100$ & $>100$ & $>100$ \\
\hline T. indica & $14.76 \pm 2.73$ & $>100$ & $>100$ & $92.57 \pm 0.94$ \\
\hline$V$. vinifera & $>100$ & $>100$ & $>100$ & $>100$ \\
\hline TTW & $>100$ & $>100$ & $>100$ & $47.12 \pm 3.14$ \\
\hline TTE & $52.33 \pm 2.05$ & $>100$ & $>100$ & $>100$ \\
\hline
\end{tabular}

TTE = ethanolic extract of the Thai traditional cancer remedy; TTW = aqueous extract of the Thai traditional cancer remedy.

cytotoxicity $\left(\mathrm{IC}_{50}>20 \mu \mathrm{g} / \mathrm{ml}\right)$ against all tested cancer cells with low toxicity to normal cells $(\mathrm{SI}>2)$. H. indicum and F. vugare also selectively exerted mild to moderate cytotoxicity against the cancer cells.

Flavonoids, a group of phenolic compounds found in several medicinal plants, have a diverse range of derivatives depending on the substituted groups on their skeletal structure. This variety of flavonoids make the medicinal plants more valuable for their role in health promotion and prevention of several chronic diseases including cancer. In this study, we investigated the total flavonoid contents of the plants and analyzed their correlation with cytotoxicity against cancer cells. As shown in Figure 1, the total flavonoid content of the extracts exhibited weak or no correlation to cytotoxicity against all tested cancer cells with coefficient $(r)$ less than 0.35. However, in MCF-7, when the outlier data were excluded and the correlation recalculated, some extracts showed a strong correlation between total flavonoid 
Table 3: Selectivity index (SI) of cytotoxic activity and total flavonoid content of the plant and remedy extracts.

\begin{tabular}{|c|c|c|c|c|}
\hline \multirow{2}{*}{ Plant extracts } & \multicolumn{3}{|c|}{ Selectivity index (SI) } & \multirow{2}{*}{ Total flavonoid (mean \pm SEM; mg quercetin eq./g) } \\
\hline & HaCat/MCF7 ratio & HaCat/SKOV3 ratio & HaCat/Hela ratio & \\
\hline A. ebracteatus & 0.81 & 3.76 & 3.20 & $151.32 \pm 3.59$ \\
\hline A. galanga & 2.68 & 2.76 & 2.67 & $140.84 \pm 4.47$ \\
\hline A. villosum & 1.70 & 0.65 & 0.88 & $79.72 \pm 7.94$ \\
\hline A. comosus & 1.00 & 1.00 & 1.00 & $75.07 \pm 4.14$ \\
\hline A. paniculata & 0.44 & 0.38 & 0.38 & $96.1 \pm 5.87$ \\
\hline A. sinensis & 2.09 & 0.80 & 0.99 & $246.56 \pm 2.58$ \\
\hline A. dahurica & 10.13 & 1.00 & 1.00 & $227.95 \pm 5.69$ \\
\hline A. valgaris & 0.56 & 0.77 & 0.59 & $64.83 \pm 3.47$ \\
\hline A. membranaceus & 1.00 & 1.00 & 1.00 & $185.91 \pm 6.78$ \\
\hline B. rotunda & 1.14 & 0.98 & 0.57 & $175.38 \pm 5.19$ \\
\hline C. halicacalum & 2.19 & 1.00 & 1.00 & $138.29 \pm 3.98$ \\
\hline C. papaya & 2.37 & 1.00 & 1.00 & $134.27 \pm 2.61$ \\
\hline C. verum & 2.21 & 1.00 & 1.91 & $220.97 \pm 4.12$ \\
\hline C myrrha & 1.00 & 1.00 & 1.45 & $143.77 \pm 4.37$ \\
\hline C. stellatopilosus & 0.39 & 0.34 & 0.34 & $46.38 \pm 5.02$ \\
\hline C. aromatic & 0.10 & 0.09 & 0.09 & $259.7 \pm 3.21$ \\
\hline C. Comosa & 0.57 & 0.64 & 0.54 & $139.28 \pm 3.04$ \\
\hline D. opposite & 1.00 & 1.00 & 1.00 & $113.73 \pm 5.71$ \\
\hline E. acoroides & 1.00 & 1.00 & 1.00 & $31.96 \pm 2.29$ \\
\hline F. albopurpurea & 6.83 & 1.00 & 1.00 & $25.47 \pm 2.13$ \\
\hline F. vulgare & 4.92 & 2.21 & 1.47 & $81.57 \pm 2.97$ \\
\hline H. indicum & 3.39 & 2.85 & 2.09 & $33.64 \pm 2.61$ \\
\hline E. arvense & 1.00 & 1.00 & 1.00 & $33.25 \pm 2.42$ \\
\hline J. sambac & 1.00 & 1.00 & 1.00 & $30.06 \pm 2.73$ \\
\hline K. galanga & 2.03 & 1.00 & 1.00 & $88.23 \pm 2.71$ \\
\hline L. triadra & 0.82 & 1.76 & 0.82 & $136.84 \pm 2.68$ \\
\hline L. striatum & 3.31 & 3.53 & 2.76 & $34.39 \pm 3.07$ \\
\hline L. barbarum. & 1.00 & 1.00 & 1.00 & $85.6 \pm 2.98$ \\
\hline M. cochinchinensis & 0.71 & 0.38 & 0.38 & $93.77 \pm 3.4$ \\
\hline M. siamensis & 2.97 & 0.33 & 0.33 & $204.94 \pm 2.72$ \\
\hline M. ferrea & 0.08 & 0.07 & 0.07 & $216.49 \pm 7.31$ \\
\hline M. elengi & 1.00 & 1.00 & 1.00 & $190.5 \pm 3.54$ \\
\hline M. fragrans & 0.51 & 0.33 & 0.33 & $72.23 \pm 3.59$ \\
\hline N. nucifera & 1.00 & 1.00 & 1.00 & $82.43 \pm 2.53$ \\
\hline O. tenuiflorum & 1.88 & 0.95 & 0.95 & $124.35 \pm 2.74$ \\
\hline P. amarus & 3.24 & 2.61 & 2.14 & $164.6 \pm 6.21$ \\
\hline P. cablin & 4.06 & 1.00 & 1.00 & $73.58 \pm 4.98$ \\
\hline R. glutinosa & 1.00 & 1.00 & 1.00 & $101.58 \pm 2.06$ \\
\hline R. nasutus & 1.52 & 2.07 & 1.00 & $183.57 \pm 5.46$ \\
\hline S. chinensis. & 1.00 & 1.00 & 1.00 & $94.79 \pm 5.57$ \\
\hline S. indicum & 1.00 & 1.00 & 1.00 & $163.17 \pm 3.44$ \\
\hline T. indica & 6.27 & 0.93 & 0.93 & $158 \pm 5.50$ \\
\hline V. vinifera & 1.00 & 1.00 & 1.00 & $14.8 \pm 2.73$ \\
\hline TTW & 0.47 & 0.47 & 0.47 & $41.92 \pm 4.04$ \\
\hline TTE & 1.91 & 1.00 & 1.00 & $105.67 \pm 4.33$ \\
\hline
\end{tabular}

content and cytotoxicity with the coefficient of -0.81 (Figure 2). This indicated that flavonoids found in plants such as $T$. indica, B. rotunda, and $A$. dahurica might be related to their cytotoxicity against MCF-7.

Several flavonoids from $T$. indica have been reported, including vitexin, isovitrexin, orientin, and iso-orientin [13]. A previous report showed that vitexin and orientin exhibited mild to moderate cytotoxic activity against MCF-7 cell line with $\mathrm{IC}_{50}$ more than $50 \mu \mathrm{g} / \mathrm{ml}$ [14]. Another report showed that the rhizome of $B$. rotunda contained flavonoids and chalcone compounds such as alpinetin, pinocembrin, cardamonin, pinostrobin, and panduratin A [15]. A cyclohexenyl chalcone, panduratin A, in B. rotunda showed potent cytotoxic activity against MCF-7 with $\mathrm{IC}_{50}$ of $3.75 \mu \mathrm{g} /$ $\mathrm{ml}$ [16]. A. dahurica showed high flavonoid content and exerted potent cytotoxic activity against MCF-7. The major constituents of $A$. dahurica were furocoumarins, imperatorin, phelloptorin, and isoimperatorin [17]. Imperatorin and isoimperatorin exhibited low to moderate cytotoxic activity against L1210, HL-60, K562, and B16F10 cell lines [18]. Components found in $M$. siamensis are coumarins such as mammea A, mammea B, mammea $\mathrm{E}$, and other derivatives. Mammea A/AA exerted potent cytotoxic activity against breast cancer (MDA-MB-231) [19]. In P. amarus, the 


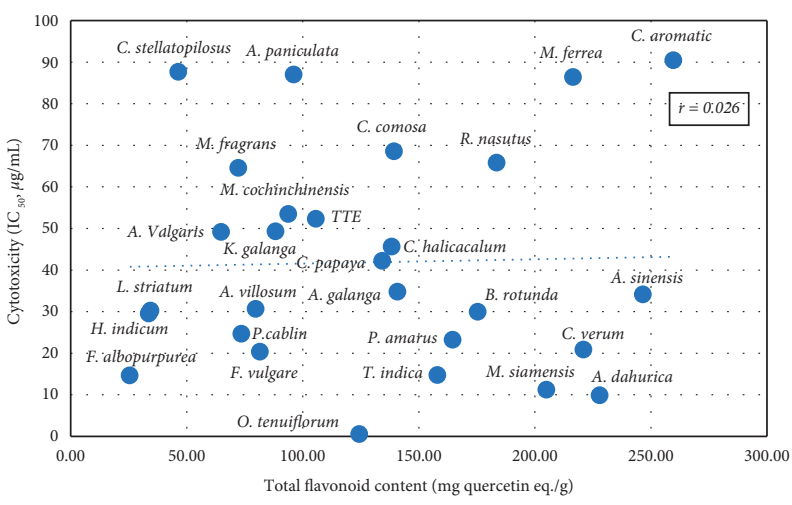

(a)

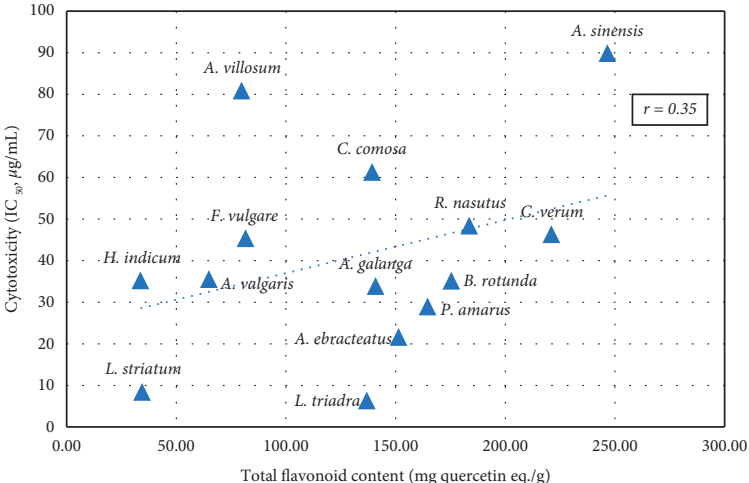

(b)

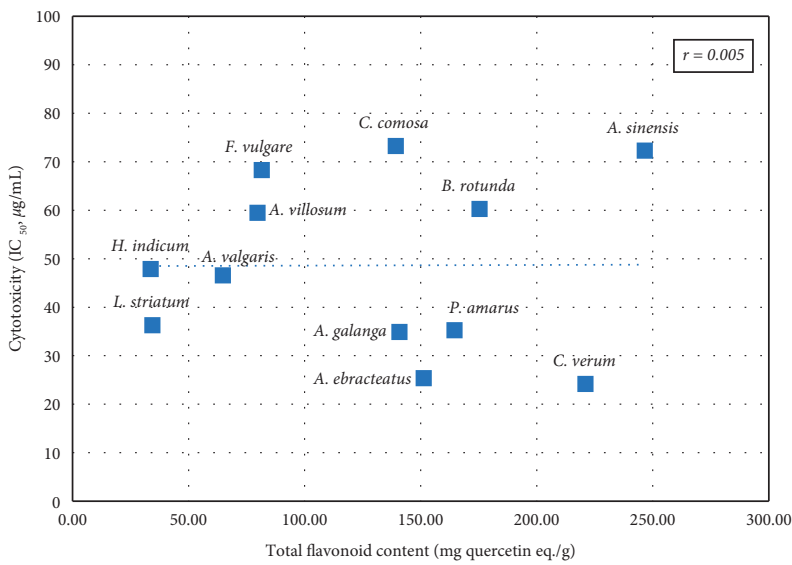

(c)

FIGURE 1: Scatter plots of flavonoid content and cytotoxicity of the plant extracts $\left(\mathrm{IC}_{50}<100 \mu \mathrm{g} / \mathrm{ml}\right)$ against cancer cell lines. $r=$ correlation coefficient, (a) = MCF-7, (b) = SKOV, (c) = Hela.

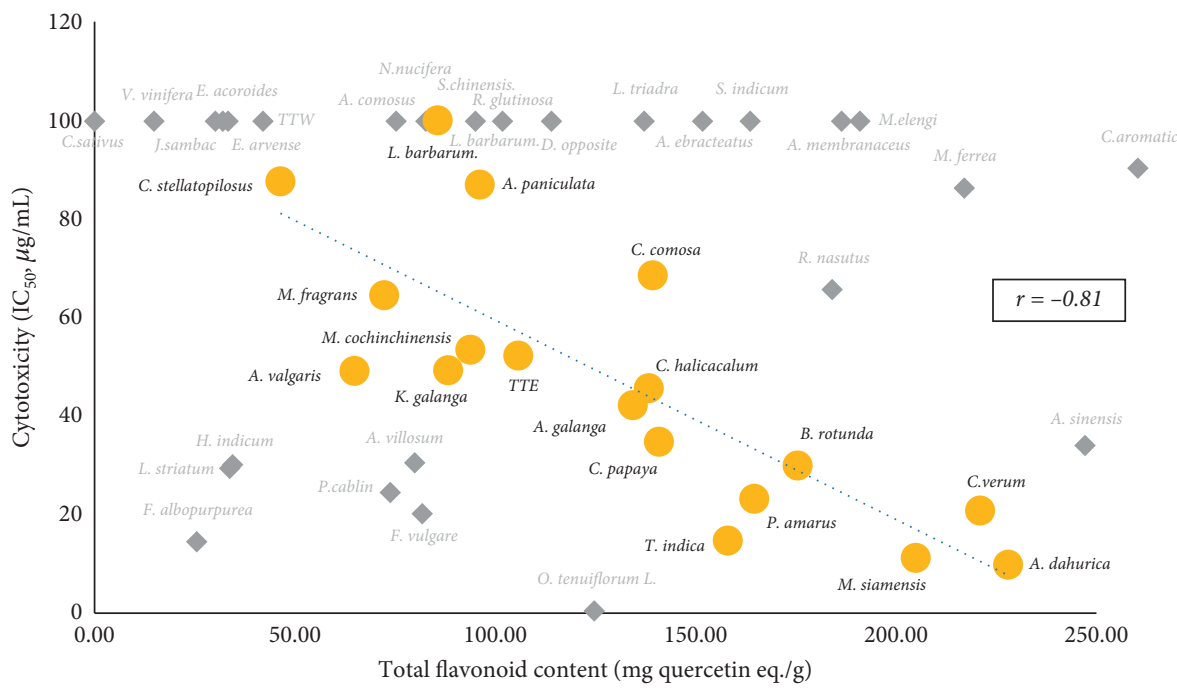

Figure 2: Scatter plot of cytotoxicity to MCF-7 and total flavonoid content of some selected plant extracts. $r=$ correlation coefficient. $(O)=$ the selected plant extracts that showed the correlation between total flavonoid content and cytotoxicity with correlation coefficient $(r)$ value $-0.81 ;(\Delta)=$ the plant extracts that showed lesser correlation.

major chemical components are lignans. Crude methanolic extract of $P$. amarus exerted cytotoxic activity against MCF7 and could reduce invasion, migration, and adhesion [20].
C. aromatica showed the highest content of flavonoids; however, it exerted mild cytotoxicity to all tested cancer cells indicating that the flavonoids in C. aromatica were not 


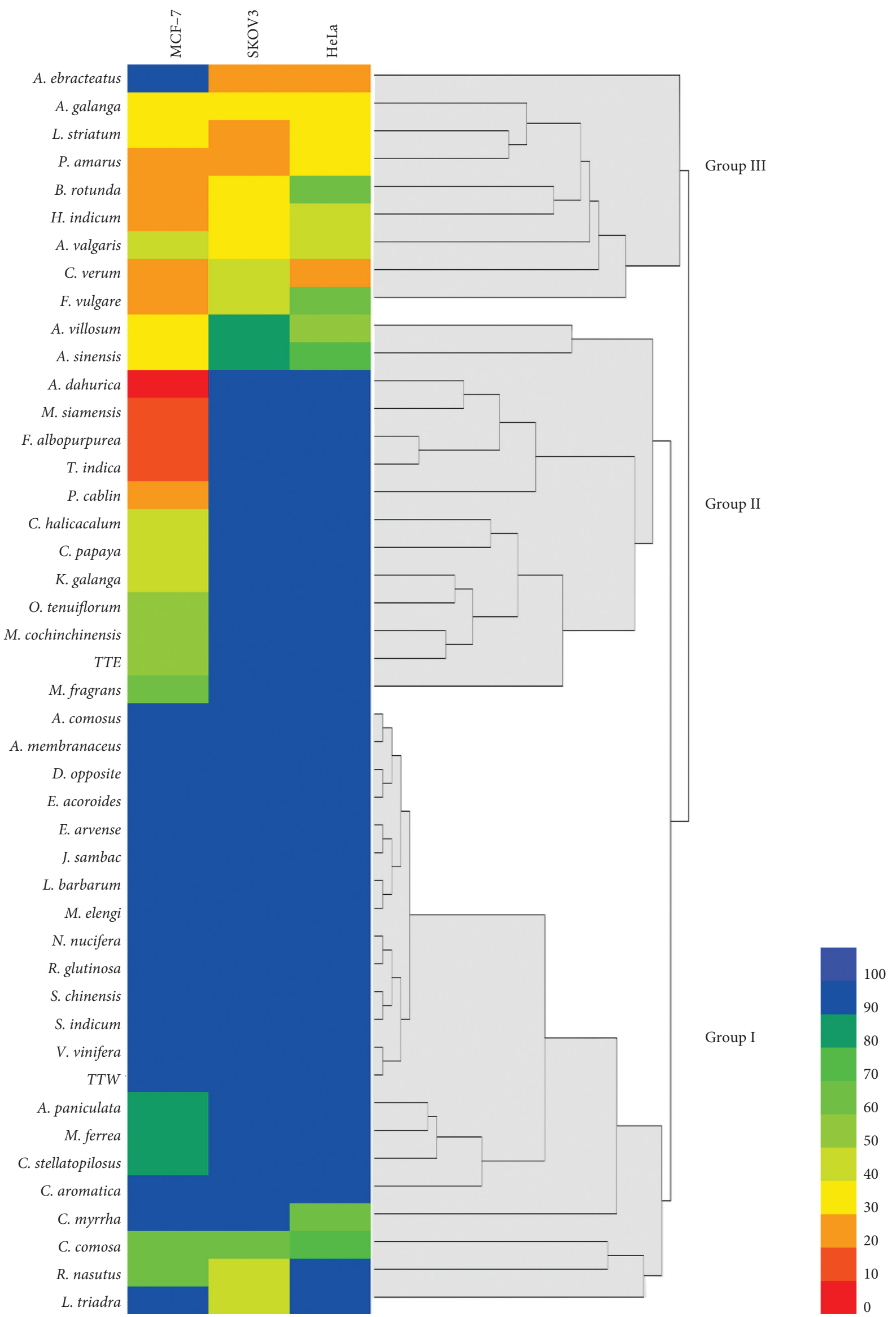

FIGURE 3: Heat map and hierarchical cluster analysis of plant and remedy extracts. Color scale bar showed a range of $\mathrm{IC}_{50}$, red color bar represents more potent cytotoxic activity $(0-10 \mu \mathrm{g} / \mathrm{ml})$ incrementing to a blue color bar which represents weak cytotoxic activity $(90-100 \mu \mathrm{g} / \mathrm{ml})$. 
related to cytotoxicity against the cancer cells. Major chemical constituents found in C. aromatica were volatile terpenes, sesquiterpenes, and curcuminoids. These compounds may react with the chemicals used in the total flavonoid assay leading to the overestimation of the values [21]. C. verum also showed high content of flavonoids, the major components being cinnamaldehyde and methyl eugenol [22].

Among the plants that showed high total flavonoid content, C. aromatica extract which possessed the highest flavonoid content exerted mild cytotoxic activity while A. dahurica exerted potent cytotoxicity. This indicated that the flavonoids in $C$. aromatica differed from those in A. dahurica, leading to the differences in their cytotoxic activity. In phytochemical reviews, the major constituent in C. aromatica is terpenes, while in A. dahurica are furocoumarins. These indicated that these compounds might cause overestimation of total flavonoid content, which underscores the limitation of this study. Hence, the determination of the total flavonoid content of the plants alone may be insufficient to describe the correlation with their biological activities. Therefore, more in-depth phytochemical studies should be pursued by more powerful analytical methods and instruments.

\section{Conclusion}

Among the 44 plants in a selected cancer remedy used for cancer treatments, 17 plants are food ingredients in Thai cuisine and nine of them exerted significant cytotoxicity against the tested cancer cell lines. Eleven plants normally used in TTM were active against at least one of the cancer cell lines, while $66.7 \%$ of all extracts were active against all the tested cell lines. The remaining plant extracts may not have any cytotoxic activity but may be necessary adjuvants according to the TTM theory which considers the correction of the imbalance of body functions as an important aspect in designing a medicine. The correlation and HCA studies provided an alternative way to investigate the biological activities of plant ingredients in polyherbal traditional remedies. This method was designed to predict the correlation between their active components and biological activities. However, the results may not show a strong correlation between the active components in traditional remedies or mixed herbs and their cytotoxicity against cancer cells. This is because only some herbs in the remedy possess cytotoxic effects while the others are included to balance other physiological functions in the body to improve patient's well-being. Therefore, in vivo studies are necessary to elucidate the true efficacy of herbal medicines. Hierarchical cluster analysis can help interpret the results of in vitro studies of herbals extracts by classifying them into groups that show different degrees of cytotoxicity in relation to the content of their bioactive components.

\section{Data Availability}

The data supporting the conclusions of the study are available from the corresponding author upon request.

\section{Conflicts of Interest}

The authors declare that they have no conflicts of interest.

\section{Acknowledgments}

This work was supported by the Centre of Excellence in Applied Thai Traditional Medicine Research, Bualuang ASEAN Chair Professorship, and Faculty of Medicine, Thammasat University, Thailand.

\section{References}

[1] B. W. Stewart and C. P. Wild, World Cancer Report 2014, World Health Organization, Lyon, France, 2014.

[2] S. Akin, G. Can, A. Aydiner, K. Ozdilli, and Z. Durna, "Quality of life, symptom experience and distress of lung cancer patients undergoing chemotherapy," European Journal of Oncology Nursing, vol. 14, no. 5, pp. 400-409, 2010.

[3] B. Poonthananiwatkul, R. H. M. Lim, R. L. Howard, P. Pibanpaknitee, and E. M. Williamson, "Traditional medicine use by cancer patients in Thailand," Journal of Ethnopharmacology, vol. 168, pp. 100-107, 2015.

[4] N. Ali and M. Hussain-Gambles, "Complementary and alternative medicine (CAM) use among South Asian patients with cancer in Britain," Diversity Health Social Care, vol. 2, no. 1, pp. 41-45, 2005.

[5] T. Tuy-on, P. Maki, and A. Itharat, "Factors affecting treatment decision with traditional Thai approach; treatment results and quality of life of cancer patients treated at the Jitmeatta Mercy Foundation for Cancer Patients of Thailand (JFCT), Phetchaburi province, Thailand," The Journal of the Thai Khadi Research Institute, vol. 18, no. 1, 2021, In press.

[6] T. Y. Wang, Q. Li, and K. S. Bi, "Bioactive flavonoids in medicinal plants: structure, activity and biological fate," Asian Journal of Pharmaceutical Sciences, vol. 13, no. 1, pp. 12-23, 2018.

[7] M. Abotaleb, S. M. Samuel, E. Varghese et al., "Flavonoids in cancer and apoptosis," Cancers (Basel), vol. 11, no. 1, p. 28, 2019.

[8] P. Skehan, R. Storeng, D. Scudiero et al., "New colorimetric cytotoxicity assay for anticancer-drug screening," JNCI Journal of the National Cancer Institute, vol. 82, no. 13, pp. 1107-1112, 1990.

[9] A. Itharat, P. J. Houghton, E. Eno-Amooquaye, P. J. Burke, J. H. Sampson, and A. Raman, "In vitro cytotoxic activity of Thai medicinal plants used traditionally to treat cancer," Journal of Ethnopharmacology, vol. 90, no. 1, pp. 33-38, 2004.

[10] Z. H. Jia, M. C. Tang, and J. M. Wu, "The determination of flavonoid contents in mulberry and their scavenging effects on superoxide radicals," Food Chemistry, vol. 64, pp. 555-559, 1999.

[11] W. Deng, Y. Wang, Z. Liu, H. Cheng, and Y. Xue, "HemI: a toolkit for illustrating heatmaps," PLoS One, vol. 9, no. 11, Article ID e111988, 2014.

[12] Wardihan, M. Rusdi, G. Alam, Lukman, and M. A. Manggau, "Selective cytotoxicity evaluation in anticancer drug screening of Boehmeria virgata (Forst) Guill leaves to several human cell lines: HeLa, WiDr, T47D and Vero," Dhaka University Journal of Pharmaceutical Sciences, vol. 12, no. 2, pp. 87-90, 2013.

[13] V. K. Bhatia, S. R. Gupta, and T. R. Seshadri, "C-glycosides of tamarind leaves," Phytochemistry, vol. 5, no. 1, pp. 177-181, 1966. 
[14] R. S. Mohammed, A. H. Abou Zeid, S. S. El Hawary, A. A. Sleem, and W. E. Ashour, "Flavonoid constituents, cytotoxic and antioxidant activities of Gleditsia triacanthos L. leaves," Saudi Journal of Biological Sciences, vol. 21, no. 6, pp. 547-553, 2014.

[15] N. A. Yusuf, M. Suffian, M. Annuar et al., "Existence of bioactive flavonoids in rhizomes and plant cell cultures of Boesenbergia rotunda (L.) Mansf. Kulturpfl," Australian Journal of Crop Science, vol. 7, no. 6, pp. 730-734, 2013.

[16] C. Kirana, G. P. Jones, I. R. Record, and G. H. McIntosh, "Anticancer properties of panduratin A isolated from Boesenbergia pandurata (Zingiberaceae)," Journal of Natural Medicines, vol. 61, no. 2, pp. 131-137, 2007.

[17] J. Kang, L. Zhou, J. Sun et al., "Chromatographic fingerprint analysis and characterization of furocoumarins in the roots of Angelica dahurica by HPLC/DAD/ESI-MS ${ }^{\mathrm{n}}$ technique," Journal of Pharmaceutical and Biomedical Analysis, vol. 47, no. 4-5, pp. 778-785, 2008.

[18] P. N. Thanh, W. Jin, G. Song, K. Bae, and S. S. Kang, "Cytotoxic coumarins from the root of Angelica dahurica," Archives of Pharmacal Research, vol. 27, no. 12, pp. 1211-1215, 2004.

[19] C. Noysang, N. Kretschmer, O. Kunert et al., "Cytotoxic activity of mammea type coumarins from Mammea siamensis flowers," Planta Medica, vol. 75, no. 9, p. 981, 2009.

[20] J. R. Patel, P. Tripathi, V. Sharma, N. S. Chauhan, and V. K. Dixit, "Phyllanthus amarus: ethnomedicinal uses, phytochemistry and pharmacology: a review," Journal of Ethnopharmacology, vol. 138, no. 2, pp. 286-313, 2011.

[21] A. Pintatum, W. Maneerat, E. Logie et al., "In vitro antiinflammatory, anti-oxidant, and cytotoxic activities of four curcuma species and the isolation of compounds from curcuma aromatica Rhizome," Biomolecules, vol. 10, no. 5, p. E799, 2020.

[22] A. Gursale, V. Dighe, and G. Parekh, "Simultaneous quantitative determination of cinnamaldehyde and methyl eugenol from stem bark of Cinnamomum zeylanicum Blume using RPHPLC," Journal of Chromatographic Science, vol. 48, no. 1, pp. 59-62, 2010. 